\title{
Effect of increased wall thickness on indices of left ventricular pump function in children
}

\author{
Armin Wessel, Walter C Schüller, Telat M Yelbuz, Joachim H Bürsch
}

\begin{abstract}
Objective-To investigate whether augmented chamber performance in children with a concentric hypertrophied left ventricle is due to increased myocardial shortening or a geometric effect of the thickened ventricular wall.

Design-Chamber performance in terms of fractional area change and myocardial shortening - that is, circumferential midwall shortening-were measured by cross sectional echocardiography in young people with normal left ventricles and those with concentric hypertrophy of the left ventricle.
\end{abstract}

Patients-52 healthy infants, children, and young people (age range $3 \frac{1}{2}$ weeks to 26 years; body weight $1.8-89 \mathrm{~kg}$ (mean $23.6 \mathrm{~kg}$ )) and 29 infants, children, and adolescents with ventricular hypertrophy (mean body weight $31.4 \mathrm{~kg}$, age range 4 weeks to $18 \cdot 7$ years).

Main outcome measures-Chamber areas, fractional area change, midwall circumferential shortening normalised to body weight.

Results-In the controls normalised reference values were: end diastolic cavity area, $1.47(0.25) \quad \mathrm{cm}^{2} / \mathrm{kg}^{0.65}$; fractional area change, $0.56(0.03)$; end diastolic myocardial area, $1.62(0.25) \mathrm{cm}^{2} / \mathrm{kg}^{0.55}$; midwall circumferential shortening, 0.21 $(0 \cdot 03)$. By comparison, the patients had normal chamber areas (end diastolic myocardial area, $\left.1.57(0.42) \mathrm{cm}^{2} / \mathrm{kg}^{0.65}\right)$, increased fractional area change, 0.68 $(0.05)(P<0.001)$, and normal midwall circumferential shortening, $0.21(0.03)$. There was a significant relation between the degree of hypertrophy (in terms of end diastolic myocardial area) and pump function while midwall shortening remained constant: $0.08 \times$ end diastolic myocardial area $+0.44(r=0.74, P<$ 0.001).

Conclusions-The relation between myocardial shortening, wall thickness, and fractional area change emphasises that the augmentation of pump function variables in left ventricular hypertrophy in young people is an effect of the thickened wall and not necessarily due to increased myocardial shortening. This relation offers the possibility of assessing the adequacy of chamber performance with respect to the degree of hypertrophy.

(Br Heart f 1994;72:182-185)
Left ventricular function is generally assessed by measuring pump function variables derived from chamber dynamics. In left ventricular hypertrophy such results may lead to misjudgment of myocardial shortening if wall thickness is not considered. This has been recognised in adults with left ventricular hypertrophy, in whom variables measuring pump function are normal while myocardial shortening, as assessed from midwall dynamics, is subnormal. ${ }^{12}$ In children, however, concentrically hypertrophied left ventricles show hyperdynamic chamber performance ${ }^{3-5}$; the question then arises whether their increased pump function is due to augmented myocardial shortening or is simply a geometric effect of increased wall thickness.

The answer to this question requires analysis of wall dynamics in concentric hypertrophied left ventricles in young people. Furthermore, such an evaluation might elucidate the normal relation between wall thickness, myocardial shortening, and chamber performance-that is, pump function-in concentrically hypertrophied left ventricles. Clinically, routine knowledge about this relation may help in assessing pump function with respect to the degree of hypertrophy in individual patients.

To evaluate this relation we measured circumferential shortening of the ventricular wall and chamber performance in normal and concentrically hypertrophied left ventricles in the young patients and controls by cross sectional echocardiography.

Patients and methods

Cross sectional echocardiograms of the left ventricle at the level of the high papillary muscle were obtained with a Sonos 100 or Sonos 1000 echocardiography system (Hewlett Packard, Andover, Massachusetts, USA). After storage on video tape quantitative geometric analysis was performed via a digital image loop by means of the Sonos 1000 analysis program package. Epicardial and endocardial contours of the left ventricle were manually traced according to the leading edge method. ${ }^{6}$ Papillary muscle was included in the cavity area.

From these contours circumferences of the epicardium and endocardium $\left(\mathrm{C}_{\text {epi }}, \mathrm{C}_{\text {endo }}\right)$ as well as areas enclosed by epicardium $\left(\mathrm{A}_{\mathrm{epi}}\right)$ and endocardium (cavity area, A) were measured in end diastole (ED) and end systole (ES). The mean of three consecutive heart beats was taken for calculation of further variables: 
Table 1 Geometrical data for normal and hypertrophied left ventricles

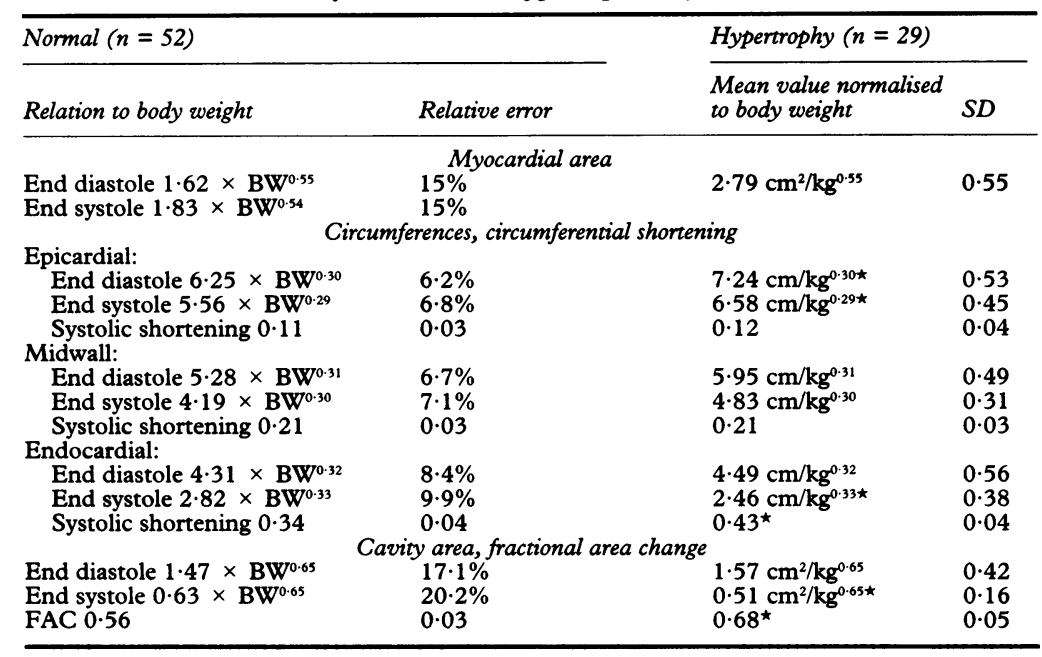

$\star \mathrm{P}<0.01 v$ normal values. FAC, fractional change.

(1) Myocardial area $=\mathrm{A}_{\mathrm{epi}}-\mathrm{A}$.

(2) Midwall circumference $=2 / 3\left(\left(\mathrm{C}_{\mathrm{epi}}{ }^{3}-\right.\right.$ $\left.\left.\mathrm{C}_{\text {endo }}{ }^{3}\right) /\left(\mathrm{C}_{\text {epi }}{ }^{2}-\mathrm{C}_{\text {endo }}{ }^{2}\right)\right)$.

As it is based on the size of the myocardial volume and area the midwall circumference takes into account the increased thickening of the inner myocardial layers. Therefore heart cycle related migration towards the endocardium is avoided. ${ }^{2}$ Hence midwall circumference is appropriate to analyse myocardial shortening of a midwall fibre layer. ${ }^{2}$

(3) Systolic shortening of the circumference $=(\mathrm{EDC}-\mathrm{ESC}) / \mathrm{EDC}$.

(4) Fractional change of the cavity area = (EDA - ESA)/EDA.

Measurements were performed in 29 infants, children, and adolescents with left ventricular hypertrophy due to aortic stenosis (20 patients) and coarctation (nine) (aged 4 weeks to 18.7 years (mean 8.6 years) and weighing $2 \cdot 8$ to $80 \mathrm{~kg}$ (mean $23.6 \mathrm{~kg}$ )). The left ventricle was considered to be hypertrophied if its myocardial area exceeded the normal mean value plus $2 \mathrm{SE}$ of the mean.

Data from normal left ventricles of 52 healthy infants, children, and young people served as reference values. Their age ranged from $3 \frac{1}{2}$ weeks to 26 years and their body weight from $1.8 \mathrm{~kg}$ to $89 \mathrm{~kg}$ (mean $23.6 \mathrm{~kg}$ ).

As in previous studies, ${ }^{7}$ normal growth relations of geometric variables were described as power functions versus body weight (BW)

Figure 1 Relation between body weight and midwall circumference at end diastole $(\diamond)$ and end systole $(\diamond)$ in healthy infants, children, and young people. Means with \pm 2 SEM (dotted lines) are depicted.

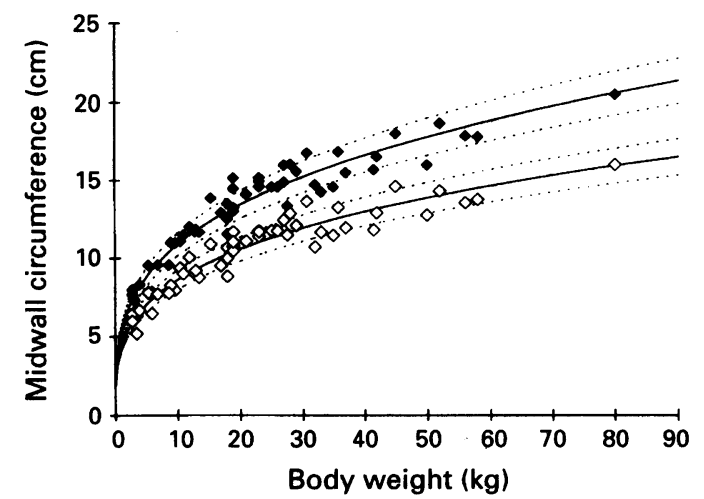

given as the mean $\pm \operatorname{SEM}(\mathrm{s}): \mathrm{y}=\mathrm{a} \times \mathrm{BW}^{\mathrm{b}}$ (s). To allow interindividual comparison mean values were normalised to powered body weight according to the normal relation. These values were marked by " $n$ ": $Y n=$ $\mathbf{y} / \mathbf{B W}^{\mathrm{b}}=\mathrm{a}$. Variables independent of body weight are given as means (SD).

Length was measured in $\mathrm{cm}$, area in $\mathrm{cm}^{2}$, and body weight in $\mathrm{kg}$. Statistical analysis was performed by Student's $t$ test.

To assess the accuracy of border definition by manual tracing in hypertrophied ventricles the interobserver error was evaluated from 30 subjects with normal and 20 patients with hypertrophied ventricles. Neither group differed significantly with regard to body weight $(19.3(13) \mathrm{kg} v 28.6(22 \cdot 6) \mathrm{kg})$. The interobserver variation was considered to be insignificant if the $99 \%$ confidence intervals of the mean difference included zero. The repeatability coefficient ${ }^{8}$ gave the range covered by of $95 \%$ of the differences.

\section{Results}

NORMAL LEFT VENTRICLE

Myocardium - The relation between myocardial area and body weight may be described by power functions (table 1), and the mean end diastolic myocardial area normalised to body weight $\left(\mathrm{MyA}_{n}\right)$ was taken as reference for interindividual comparison: $\mathrm{MyA}_{\mathrm{n}}=1.62(0.25) \mathrm{cm}^{2} / \mathrm{kg}^{0.55}$. There was a linear interdependence between end diastolic (ED) and end systolic (ES) values: $\mathrm{MyA}$ ES = $1.09 \times$ MyA ED (relative error $9 \%$ ).

Circumferences-Epicardial, midwall (fig 1), and endocardial circumferences were related to body weight, with exponents between 0.29 and 0.33 and indicating almost the same growth rate for all three variables (table 1). But systolic shortening of the circumferences was independent of body weight and increased gradually from the epicardium to the endocardium.

Cavity-The size of the left ventricular cavity in the short axis view increased with body weight (table 1). Fractional area change as a measure of ventricular pump function remained independent from body weight.

\section{LEFT VENTRICULAR HYPERTROPHY}

Myocardium-According to the definition of left ventricular hypertrophy in this study the individual end diastolic myocardial area exceeded the mean plus 2 SEM-that is, $\mathrm{MyA}_{\mathrm{n}}>2.12 \mathrm{~cm}^{2} / \mathrm{kg}^{0.55}$ (table 1).

Circumferences-The epicardial circumferences of the hypertrophied ventricles exceeded the normal range in both heart phases (table 1). The midwall circumferences did not differ significantly from normal values. The endocardial circumferences were normal in end diastole but because of augmented endocardial shortening they became subnormal in end systole (table 1). Consequently, systolic shortening of the endocardial circumference was increased and exceeded the normal range. Systolic shortening of the epicardial and midwall circumfer- 
Figure 2 Midwall circumferential shortening in children with left ventricular hypertrophy. Hatching shows mean (SD) values.

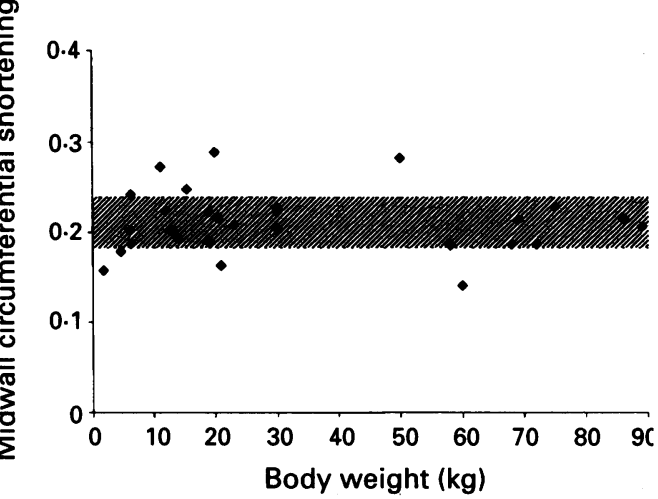

ence remained within the normal range (figure 2). The latter differs from conventional mean circumferential shortening $\left(\mathrm{CS}_{\mathrm{m}}=1 / 2 \quad\left(\mathrm{C}_{\text {endo }}+\mathrm{C}_{\mathrm{epi}}\right)\right)$, which was also increased in hypertrophied ventricles $\left(\mathrm{CS}_{\mathrm{m}}=\right.$ $0.24(0.03) v \mathrm{CS}_{\mathrm{m}}=0.21(0.03)$ in controls).

Cavity-As expected for concentric left ventricular hypertrophy, the end diastolic cross sectional area of the cavity was insignificantly larger than in normal left ventricles (table 1). Because of the exaggerated endocardial shortening, however, the end systolic cavity area became smaller than normal, thus causing a significant rise in the fractional area change (table 1 ).

\section{EFFECT OF LEFT VENTRICULAR HYPERTROPHY} ON PUMP FUNCTION

As mentioned above, the average systolic shortening of the midwall circumference was normal in hypertrophied left ventricles. But fractional area change increased with the degree of hypertrophy-that is, myocardial area: $\mathrm{FAC}=0.08 \times \mathrm{MyA}_{\mathrm{n}}+0.44 ;(r=0.74, \mathrm{~s}$ $=7 \cdot 7 \%)$. This relation implies that variables measuring chamber performance are dependent on wall thickness while the extent of myocardial shortening is not affected by hypertrophy-that is, the special geometry of a thick walled ventricle.

INTEROBSERVER ERROR

The interobserver error was determined for the variables in table 2 . The mean differences were not significantly different between the observers as the $99 \%$ confidence interval

Table 2 Statistical data for interobserver error for measurements in normal and hypertrophied left ventricles

\begin{tabular}{lccl}
\hline & Normal & Hypertrophy & P value \\
\hline & End diastolic area $\left(\mathrm{cm}^{2}\right)$ & & \\
Mean difference & 0.165 & 0.164 & $\mathrm{NS}$ \\
99\% Confidence interval & -0.165 to +0.495 & -0.418 to +0.746 & \\
Repeatability coefficient & 1.311 & 1.821 & \\
& Fractional area change & -0.030 & $\mathrm{NS}$ \\
Mean difference & -0.014 & -0.061 to +0.009 & \\
99\% Confidence interval & -0.029 to +0.001 & \\
Repeatability coefficient & 0.060 & $\mathrm{NS}$ \\
& End diastolic midwall circumference $(\mathrm{cm})$ & 0.024 \\
Mean difference & -0.007 & -0.181 to +0.229 & \\
99\% Confidence interval & -0.139 to +0.125 & 0.643 & \\
Repeatability coefficient & 0.524 & $\mathrm{NS}$ \\
& Systolic shortening of midwall circumference & \\
Mean difference & -0.004 & -0.004 \\
99\% Confidence interval & -0.011 to +0.003 & -0.018 to +0.010 & \\
Repeatability coefficient & 0.026 & 0.044 & \\
\hline
\end{tabular}

included zero. There was also no significant difference between the measurements from normal and hypertrophied ventricles.

\section{Discussion}

Clinical use of echocardiography is convenient to assess ventricular function by measuring variables derived from dimensional changes of the cavity (fractional area change or ejection fraction). Usually the geometry of the ventricle is assumed to be normal, but it is not so in left ventricular hypertrophy because the wall is thickened. This problem is well recognised in adults, ${ }^{12}$ but, to our knowledge, no reports deal with the effects of left ventricular hypertrophy on variables of chamber performance in children.

Before comparison of geometrical data from growing children becomes feasible it is necessary to evaluate the normal relations between body weight and the variables of interest. These relations were represented in terms of power functions based on the data from 52 healthy young subjects (fig 1). Interindividual comparison of actual measurements was performed after normalising each of them to the powered body weight derived from the normal curve. Normalisation was not necessary for functional variables because they were independent of weight (fig 2).

Definition of left ventricular hypertrophy was based on the size of the myocardial cross sectional area, which had to exceed the normal mean + 2SEM. Thus only ventricles with significant hypertrophy were considered.

Circumferential shortening increased from the epicardium to the endocardium in normal and hypertrophied ventricles. This is in accordance with reports from adults. ${ }^{12}$ The inhomogeneity of shortening throughout the wall may explain the overestimation of myocardial shortening when measuring endocardial or chamber dimensions. ${ }^{9}$ This also affects the conventional mean circumference $\left(C_{m}=1 / 2\right.$ $\left(\mathrm{C}_{\text {endo }}+\mathrm{C}_{\text {epi }}\right)$ ) because the non-uniform thickening of the wall causes a migration of this special circumference towards the endocardium. To avoid this disadvantage we measured midwall circumference. The calculation of this variable is based on the assumption that the midwall circumference divides the wall into two compartments, each containing the same number of myocardial fibres irrespective of the heart phase. Consequently this circumference remains in a stable midwal position during the cardiac cycle and enables reliable measurements of midwall shortening.

Chamber performance in terms of fractional area change depends on both circumferential shortening and wall thickness. This is supported by figure 3, which depicts the relation between wall thickness-that is, degree of hypertrophy in terms of the end systolic ratio (MyA/A)-midwall circumferential shortening (MCS), and fractional area change. The curves are derived from our data and based on the relation $\mathrm{MyA}_{\mathrm{ES}} / \mathrm{MyA}_{\mathrm{ED}}=1.09$ shown above. Values away from the normal range were obtained from hypertrophied ventricles, 


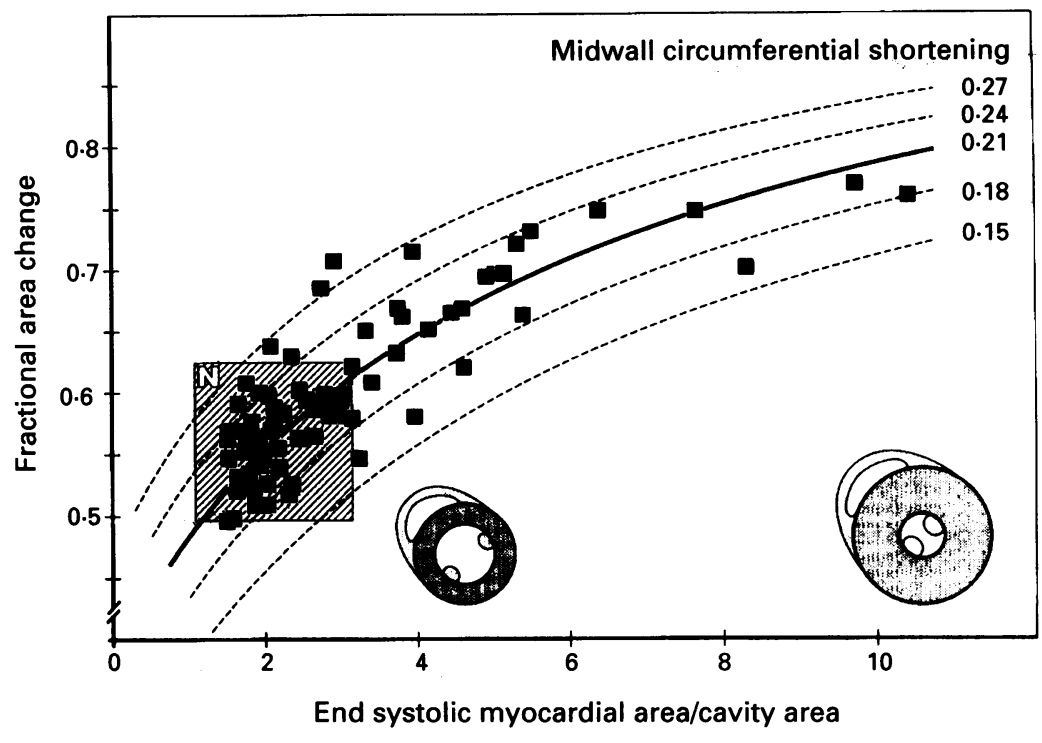

Figure 3 Degree of left ventricular hypertrophy ( $\times$ axis) and midwall circumferential shortening (curves) affect fractional area change in hypertrophied ventricles. Hatching shows mean (SE) values (normal range). In left ventricular hypertrophy normal midwall shortening leads to increased fractional area change. On the other hand, if the ventricular wall is thickened a normal fractional area change corresponds to reduced circumferential midwall shortening - that is, impaired myocardial shortening.

which means that the fractional area change is increased while midwall circumferential shortening is normal. Thus augmented pump function in left ventricular hypertrophy may be interpreted as a geometric effect due to a thickened wall with normal myocardial shortening. This is compatible with the conclusion of Shimizu et al that normal chamber performance in left ventricular hypertrophy is due to diminished circumferential shortening. ${ }^{2}$ From a clinical point of view, figure 3 shows the possibility of measuring the appropriate chamber performance (fractional area change) in left ventricular hypertrophy.

To assess potential methodical limitations the interobserver error was determined for representative variables. According to the coefficient of reproducibility, the reliability in our study was equivalent to that obtained by Martins et al, who compared measurements of chamber dimensions and functional variables from transthoracic and transoesophageal $M$ mode echocardiography in young patients. ${ }^{10}$ The fact that it is more difficult to recognise endocardial borders in hypertrophied left ventricles may explain the slightly reduced reproducibility in our study, but it affected the reliability of the results only slightly.

In summary, in hypertrophied ventricles circumferential shortening is normal but the thickened wall leads to increased values for pump function variables. This geometric effect has to be considered to prevent overestimation of myocardial shortening in thick walled left ventricles.

1 Shimizu G, Zile MR, Blaustein AS, Gaasch WH. Left ventricular chamber filling and midwall fiber lengthening in patients with left ventricular hypertrophy: overestim patients with left ventricular hypertrophy: overestima-
tion of fiber velocities by conventional midwall measurements. Circulation 1985;71:266-72.

2 Shimizu G, Hirota Y, Kita Y, Kawamura K, Saito T, Gaasch WH. Left ventricular midwall mechanics in systemic arterial hypertension. Myocardial function is depressed in pressure overloaded hypertrophy. depressed in pressure

3 Donner R, Carabello BA, Black I, Spann JF. Left ventricular wall stress in compensated aortic stenosis in children. Am f Cardiol 1983;51:946-51.

4 Lange PE. Clinical relevance of video-angiocardiometry in the pediatric age group. Herz 1985;10:238-47.

5 Graham TP. Ventricular performance in congenital heart disease. Circulation 1991;84:2259-74.

6 Wyatt HL, Haendchen RV, Meerbaum S, Corday E Assessment of quantitative methods for two-dimensional echocardiography. Am ₹ Cardiol 1983;52:396-401.

7 Wessel Á. Normal values of two-dimensional echocardiographic evaluation of left and right ventricular geometry in children. Herz 1985;10:248-54.

8 Bland JM, Altman DG. Statistical methods for assessing agreement between two methods of clinical measurement. Lancet 1986;i:307-12.

9 Gascho JA, Copenhaver GL, Heitjan DF. Systolic thickening increases from subepicardium to subendocardium. Cardiovasc Res 1990;24:777-80.

10 Martins TC, Rigby ML, Redington AN. Left ventricular performance in children: transthoracic versus transoesophageal measurement of $\mathrm{M}$ mode derived indices. Br Heart $f$ 1 1992;68:485-7. 